\title{
Sequence variation at 8q24.21 and risk of back pain [version 1;
}

\section{peer review: 1 approved]}

\author{
Frances M.K. Williams1, Yakov A. Tsepilov2,3, Maxim B. Freidin', \\ Tatiana I. Shashkova (iD2,4,5, Pradeep Suri6,7, Yurii S. Aulchenko 2,3,8
}

${ }^{1}$ Department of Twin Research and Genetic Epidemiology, King's College London, London, UK

2Laboratory of Theoretical and Applied Functional Genomics, Novosibirsk State University, Novosibirsk, Russian Federation

${ }^{3}$ Laboratory of Recombination and Segregation Analysis, Institute of Cytology and Genetics SD RAS, Novosibirsk, Russian Federation

${ }^{4}$ Department of Molecular and Biological Physics, Moscow Institute of Physics and Technology (State University), Moscow, Russian Federation

${ }^{5}$ Research and Training Center on Bioinformatics, A.A. Kharkevich Institute for Information Transmission Problems RAS, Moscow, Russian Federation

${ }^{6}$ Medical Genetics, Department of Medicine, University of Washington, Seattle, Washington, USA

${ }^{7}$ Division of Rehabilitation Care Services, VA Puget Sound Health Care System, Seattle, Washington, USA

${ }^{8}$ Polyomica, 's-Hertogenbosch, The Netherlands

V1 First published: 22 May 2020, 9:424

https://doi.org/10.12688/f1000research.22725.1

Latest published: 22 May 2020, 9:424

https://doi.org/10.12688/f1000research.22725.1

\section{Abstract}

Back pain (BP) is a common condition of major social importance and poorly understood pathogenesis. Intervertebral lumbar disc degeneration in all its guises is one of the major biological risk factors for BP. Previously, we identified the locus at 8q24.21 associated with chronic BP, which has been found elsewhere associated with sciatica after surgery for lumbar disc herniation. In the current study we used co-localisation methods to identify the gene most likely to harbor the causal variant. We show that the same functional variant at the $8 q 24.21$ locus is responsible for both lumbar disc degeneration and $\mathrm{BP}$, and we also studied the effects of this locus on related phenotypes. Our results link the locus to intervertebral disc and bone mineral density, but not to anthropometric measurements, thus corroborating the epidemiological evidence. Moreover, the same functional variant at the locus is more likely to affect the expression of the nearby FAM $49 B$ gene, rather than the GSDMC gene, which was previously proposed as a causative one for BP.

Keywords

lumbar disk degeneration, back pain, transcriptomics, genome wide association study

\section{Peer review discontinued}

Peer review at F1000Research is authordriven. Currently no reviewers are being invited. What does this mean?

\section{Approval Status}

version 1

22 May 2020

$$
\text { view }
$$

\section{Lisbet Haglund ID, McGill University,}

Montreal, Canada

Any reports and responses or comments on the article can be found at the end of the article. 
Corresponding authors: Frances M.K. Williams (frances.williams@kcl.ac.uk), Yurii S. Aulchenko (y.S.aulchenko@polyomica.com)

Author roles: Williams FMK: Conceptualization, Supervision, Writing - Original Draft Preparation; Tsepilov YA: Data Curation, Formal Analysis, Investigation, Writing - Review \& Editing; Freidin MB: Data Curation, Formal Analysis, Writing - Review \& Editing; Shashkova TI : Formal Analysis, Writing - Review \& Editing; Suri P: Data Curation, Formal Analysis, Writing - Review \& Editing; Aulchenko YS: Conceptualization, Supervision, Writing - Original Draft Preparation

Competing interests: YSA is a co-owner of Maatschap PolyOmica and PolyKnomics BV, private organizations, active in re-search and development in the field of computational and statistical (gen)omics. Other authors declare no competing interest.

Grant information: This work was funded by the EU FP7 PainOMICS project [grant agreement \# 602736]. TIS was sup-ported by the Russian Ministry of Science and Education under the 5-100 Excellence Programme. YSA was supported by the Federal Agency of Scientific Organizations via the Institute of Cytology and Genet-ics [project 0324-2019-0040-C-01]. YAT was supported by the Federal Agency of Scientific Organiza-tions via the Institute of Cytology and Genetics [project 0324-2019-0040-C-01] and by the Russian Foundation for Basic Research [project 19-015-00151]. The Genotype-Tissue Expression (GTEx) Pro-ject was supported by the Common Fund of the Office of the Director of the National Institutes of Health, and by NCI, NHGRI, NHLBI, NIDA, NIMH, and NINDS. The data used for the analyses described in this manuscript were obtained from the GTEx Portal on February 2017. The CEDAR was supported by grants to Michel Georges from WELBIO (CAUSIBD), BELSPO (BeMGI), and Horizon 2020 (SYS-CID).

The funders had no role in study design, data collection and analysis, decision to publish, or preparation of the manuscript.

Copyright: (c) 2020 Williams FMK et al. This is an open access article distributed under the terms of the Creative Commons Attribution License, which permits unrestricted use, distribution, and reproduction in any medium, provided the original work is properly cited.

How to cite this article: Williams FMK, Tsepilov YA, Freidin MB et al. Sequence variation at 8q24.21 and risk of back pain [version 1; peer review: 1 approved] F1000Research 2020, 9:424 https://doi.org/10.12688/f1000research.22725.1

First published: 22 May 2020, 9:424 https://doi.org/10.12688/f1000research.22725.1 


\section{Introduction}

Back pain (BP) is a common debilitating condition with a lifetime prevalence of $40 \%$ and a major socioeconomic impact $^{1}$. According to the Global Burden of Disease 2016 study, it leads the list of disabling conditions in many parts of the world $^{2}$. The greatest biological risk for episodes of severe BP is thought to be lumbar disc degeneration (LDD) ${ }^{3}$. Rather than a discrete disease, LDD is now considered a continuous lifelong aging process that usually starts in the third decade of life but may also be seen in children ${ }^{4}$. It is highly heritable ${ }^{5}$, as well as being influenced by smoking ${ }^{6}$, age ${ }^{7}$ and body mass index ${ }^{8}$. The overall burden of lumbar disc degeneration on magnetic resonance imaging is a strong predictor of BP episodes ${ }^{9-11}$. There is a clear genetic predisposition to both BP and LDD with estimates of heritability in the range of $30 \%-70 \%{ }^{12-15}$. Also, these traits have been shown to share genetic risk factors ${ }^{16}$. However, little is known about the genetic architecture of BP and only three associated genetic loci have been identified ${ }^{17,18}$.

This work was focused on the locus at chromosome 8 (8q24.21), which was identified in our previous BP studies ${ }^{17,18}$. The same locus has been reported associated with having lumbar disc herniation $(\mathrm{LDH})$ in Icelanders undergoing surgery for sciatica $^{19}$. Bjornsdottir et al. additionally reported an association of this region to height, but concluded that the region does not influence LDH through height. They noted that the most highly associated SNP, rs6651255, was linked to expression of the nearby gasdermin $(G S D M C)$ gene in GTEx data ${ }^{20}$. Further, the immune-related function of gasdermins implied that the inflammatory and immunological consequences of disk herniation may be linked to sciatica symptom severity.

However, closely located SNPs associated with different traits do not always reflect pleiotropy ${ }^{21}$. Furthermore, in the case of eQTL studies, causal hypotheses generated through singlevariant look up are highly likely to be false positives ${ }^{21}$. Consequently, a variety of co-localization methods have been introduced $^{22-25}$ to distinguish the two common scenarios: pleiotropy (the same functional genetic variant is associated with both traits) and linkage (two different functional genetic variants, each associated with a different trait, that are in linkage disequilibrium).

The aim of this study was to (1) verify whether the same functional variant at $8 \mathrm{q} 24.21$ is responsible for BP and LDH and (2) to study the effects of this variation on related phenotypes. As a result, we offer an alternative explanation to the assertion by Bjornsdottir et al. ${ }^{17}$ regarding the role of immunity and inflammation in generating symptoms of sciatica and $\mathrm{BP}$ due to variation in expression at the locus in between genes $C C D C 26$ and GSDMC.

\section{Methods}

\section{GWAS data}

We used the BP GWAS performed in all genetically confirmed white British UK Biobank participants $(\mathrm{N}=453,862)$ as target data for future analysis ${ }^{17}$. We used the summary level-data of LDH GWAS from the original paper of deCODE group ${ }^{19}$. They do not provide full GWAS scan, only the statistics for the significant SNPs from the $8 \mathrm{q} 24.21$ region. We used information about 40 SNPs from this locus for which information about effect size, effective and reference alleles and p-value was available (Supplementary Table 1,3 of the work ${ }^{19}$ ).

We derived summary statistic of 2,419 complex traits provided by the Neale Lab and 34 traits from the Gene ATLAS database. Summary statistics for gene expression levels were obtained from Westra Blood eQTL ${ }^{26}$ (peripheral blood, http://cnsgenomics.com/software/smr/\#eQTLsummarydata, file: westra_eqtl_data_hg19.zip (hg19)) and the GTEx database ${ }^{27}$ (14 tissues ${ }^{28}$, https://www.gtexportal.org/home/datasets, file: GTEx_Analysis_V6_all-snp-gene-associations.tar).

\section{SMR-HEIDI analysis}

Summary-level mendelian randomization and heterogeneity in dependent instruments (SMR-HEIDI) ${ }^{24}$ approach was used to test for potential pleiotropic effects of the $8 \mathrm{q} 24.21$ region on back pain (BP) and LDH and other complex traits including gene expression levels in certain tissues. SMR analysis provides evidence for pleiotropy, but is unable to define whether both traits are affected by the same underlying causal polymorphism. The latter is specified by a HEIDI test that distinguishes pleiotropy from linkage. Zhang F. and colleagues developed the software SMR tool implementing the SMR-HEIDI methods ${ }^{24}$.

SMR tool is suitable to analyze pleiotropic association using summary-level data from GWAS and eQTL studies. We conducted two groups of analysis: target trait vs eQTL and target trait vs other complex traits. Summary-level data from BP GWAS $^{17}$ was used as target (--gwas-summary option) in both cases. For eQTL analysis we used Westra Blood eQTL data (converted to suitable BSED format by developers) and GTEx v7, converted using --make-besd option (smr -eqtl-flist Gtex tissue 1.txt --make-besd -out Gtex tissue 1, where Gtex tissue 1.txt file correspond to summary-level data of selected tissue). In order to apply SMR tool for complex traits we selected the region $+-250 \mathrm{~kb}$ around the target SNP from each complex trait GWAS. After that, we add new columns Probe_ID with trait_ name to corresponded SNP subset. Finally, we merge these SNP subsets into one file and converted it in BESD format using --make-besd option.

In both cases we set the minor allele frequency threshold as 0.03 and included in the HEIDI test SNPs inside $+-250 \mathrm{~kb}$ window centered around the target SNP; other parameters used default settings. The LD matrix for the HEIDI test was estimated using PLINK 1.9 software and individual data of white UK Biobank participants, the subset of individuals used to calculate BP GWAS $(\mathrm{N}=10,000)$.

Nominal P for SMR test was set at $6 \mathrm{e}-4(0.05 / 89$, where 89 is the total number of probes for the gene expression analysis) and $2 \mathrm{e}-5(0.05 / 2,453$, where 2,453 is the total number of complex traits used in analysis). For HEIDI analysis we used 
a conservative threshold of $\mathrm{P}=0.05(\mathrm{P}<0.05$ corresponds to the rejection of pleiotropy hypothesis).

\section{Results and discussion}

We had previously performed the largest-to-date GWAS for chronic BP using the UK Biobank and CHARGE consortium cohorts, with total of 119384 cases and 334478 controls ${ }^{17}$. Cases were defined as those having BP of duration >3-6 months; controls included those without back pain or with back pain of <3-6 months. We found variants at $8 \mathrm{q} 41.21$ locus that showed a genome-wide significant association $(\mathrm{OR}=1.05$, $\mathrm{p}=4.4 \times 10^{-13}$, after genomic control correction $)^{17}$. The location chr8:130,717,716 is tagged by intergenic variant rs 10956487 which is in perfect LD with $\mathrm{rs6651255}\left(\mathrm{r}^{2}=1\right.$ according to 1000 Genomes EUR samples), the lead SNP in the Icelandic study of LDH by Bjornsdottir et al. ${ }^{19}$. The strongest association signal for $\mathrm{BP}$ is situated near GSDMC gene; yet another protein-coding gene, $F A M 49 B$, is located within a $500 \mathrm{kbp}$ window. The summary of the previously reported results and our findings for locus 8q24.21 are shown in Figure 1.

We used the SMR-HEIDI approach ${ }^{24}$ to test for potential pleiotropic effects of the 8q24.21 region (rs6651255) on BP and other complex traits including gene expression levels in relevant tissues. SMR analysis provides evidence for pleiotropy, but is unable to determine whether both traits are influenced by the same underlying causal polymorphism. The latter question was addressed by the HEIDI test which distinguishes pleiotropy from linkage. For SMR-HEIDI testing we used as the target trait the BP GWAS previously performed in all genetically confirmed white British UK Biobank participants ${ }^{17}$.

First of all, we checked relationships between BP and LDH. We found strong evidence that co-association of these traits to $8 \mathrm{q} 24.21$ is due to the pleiotropic action of the same functional variant $\left(\mathrm{P}_{\mathrm{SMR}}=2.8 \times 10^{-7}\right.$ and $\mathrm{P}_{\mathrm{HEIDI}}=0.87$; extended data $\left.{ }^{29}\right)$. We further applied SMR-HEIDI to test for pleiotropic effects of the region in the collection of 2,453 traits available from the UK biobank study and GeneAtlas. We found that the BP risk allele of rs6651255 was negatively associated with heel bone mineral density t-score and positively associated with selfreported prolapsed or slipped disc (both $\mathrm{FDR}_{\mathrm{SMR}}<0.01$, underlying data $^{30}$ and extended data $^{29}$ ) and also strongly associated with standing height (underlying data ${ }^{30}$ and extended data $^{29}$ ) and several measures of fat-free mass (all $\mathrm{FDR}_{\mathrm{SMR}}<0.001$ ). However, HEIDI tests showed strong evidence against pleiotropic effects of the same functional variant in this region for $\mathrm{BP}$ and these anthropometric traits (all $\mathrm{P}_{\text {HEIDI }}<0.001$ ), while associations with heel bone mineral density t-score and self-reported prolapsed or slipped disc were likely the result of pleiotropy, controlled by the same functional variant (all $\mathrm{P}_{\text {HEIDI }}>0.05$ ). This suggests that genetic variants influencing structural spine features - the vertebral body and intervertebral disc - provide the link to BP symptoms, supporting previous work in twins highlighting shared genetic influence between spine degeneration and $\mathrm{BP}^{16,31}$.

The unanticipated results were obtained in the study of expression data. We have previously ${ }^{17}$ demonstrated that variants in LD with the lead SNP at 8q24.1 were located in potential regulatory regions in chondrocytes and osteoblasts (Roadmap Epigenomics Consortium ${ }^{32}$ ). In the current study, we tested expression of genes in the $8 \mathrm{q} 24.21$ region in all available tissues considered potentially relevant to development of pain (underlying data ${ }^{33}$ ), including musculoskeletal, brain and nerve tissue (from $\mathrm{GTEx}^{20}{ }^{20}$ ). Given the suggestion by Bjornsdottir et al. that the locus may act through regulation of immune function ${ }^{19}$, we also investigated expression in whole blood using the blood eQTL database ${ }^{26}$ and five immune cell subsets from $\mathrm{CEDAR}^{34}$. Similar to the Bjornsdottir et al. study ${ }^{19}$, we observed that rs6651255 is co-associated with expression

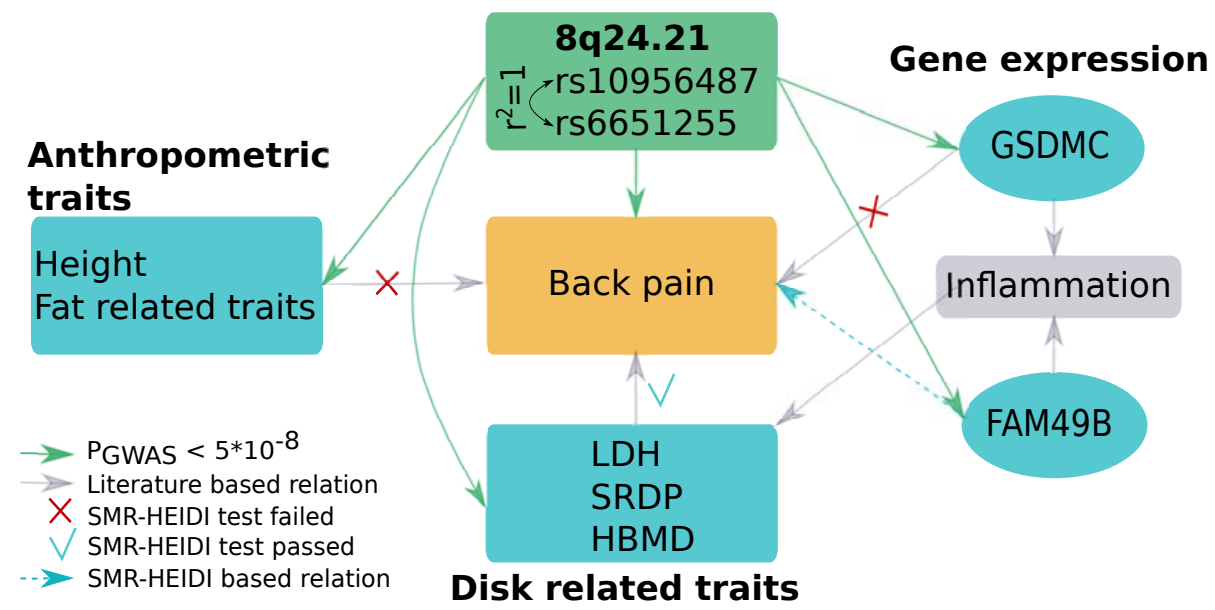

Figure 1. Pleiotropic effects of locus $\mathbf{8 q 2 4 . 2 1}$ on BP and related traits. The BP-related traits and genes analyzed in our work are blue. The locus $8 q 24.21$ is connected to associated traits $\left(p\right.$-value $\left.<5^{*} 10^{-8}\right)$ by green arrows. Possible relations between traits, as inferred from previous studies, are marked by grey arrows. Pairwise pleiotropic effects tested by SMR-HEIDI are denoted by a red cross if the test failed, and by a blue check if the test passed. A new detected pleiotropic effect on expression of FAM49B and BP based on SMR-HEIDI results is denoted by the blue arrow. LDH, lumbar disk herniation; SRDP, self-reported disk problems; HBMD, heel bone mineral density t-score. 
of GSDMC in skeletal muscle $\left(\mathrm{FDR}_{\mathrm{SMR}}=0.01, \mathrm{P}_{\mathrm{SMR}}=0.0001\right.$, underlying data ${ }^{30}$ ), with the BP-associated $\mathrm{C}$ allele of rs6651255 being associated with increased expression of the gene. However, HEIDI results show this overlap to be unlikely due to pleiotropic action of the same functional variant $\left(\mathrm{P}_{\text {HEIDI }}=3 \times 10^{-7}\right.$, underlying data ${ }^{30}$ and extended data $\left.^{29}\right)$. Our findings suggest that GSDMC is not the gene through which the functional variant acts to influence BP. The next strongest co-association was with increased expression of $F A M 49 B$ in brain anterior cingulate cortex $\left(\mathrm{P}_{\mathrm{SMR}}=0.004\right.$, underlying data ${ }^{30}$ and extended data $^{29}$ ) and decreased expression in cytotoxic $\mathrm{T}(\mathrm{CD} 8+)$ cells $\left(\mathrm{P}_{\mathrm{SMR}}=0.02\right.$, underlying data $^{30}$ and extended data $\left.^{29}\right)$, although these associations were only nominally significant $(\mathrm{p}<0.05)$, yet not statistically significant after multiple testing correction $\left(\mathrm{FDR}_{\mathrm{SMR}}=0.18\right.$ and 0.28 , respectively). All corresponding $\mathrm{P}_{\text {HEIDI }}$ were $>0.05$, indicating these co-associations are likely due to pleiotropy. The product of FAM49B was found to be expressed in multiple tissues including bone, lymph node and spleen; according to Proteomics $\mathrm{DB}^{35}$, it has highest expression in lymphocytes, and was implicated as a key negative regulator of actin dynamics and T-cell activation ${ }^{36}$. The precise mechanism of which gene is involved in the development of BP is difficult to infer due to lack of eQTL data available for relevant tissues, such as intervertebral disc.

\section{Conclusion}

We hypothesize that the locus 8q24.21 exhibits its influence on BP phenotypes via disk and bone remodeling, and not through influence on anthropometrics or pain processing. Our findings suggest that $F A M 49 B$ and not GSDMC is the most likely mechanism through which the functional variant leads to BP.

\section{Data availability}

Underlying data

Zenodo: Table S1. List of relevant studies of gene expression with available eQTL data. http://doi.org/10.5281/zenodo.3715005 ${ }^{33}$

This project contains the following underlying data:

- List of relevant studies of expression data.csv (List of relevant studies of gene expression with available eQTL data)

Zenodo: Tables S2-S3. SMR-HEIDI results for 8q24.21 locus between back pain and other phenotypes. [Data set]. http://doi. org/10.5281/zenodo. $3715027^{30}$
This project contains the following underlying data:

- SMR-HEIDI results ST2.csv (SMR-HEIDI results for 8q24.21 locus between back pain and other complex traits)

- SMR-HEIDI results ST3.csv (SMR-HEIDI results for 8q24.21 locus between back pain and expression of genes)

\section{Extended data}

Figures S1-S7. SMR-HEIDI analysis results for $8 \mathrm{q} 24.21$ locus between BP and selected phenotypes. Zenodo: http://doi. org/10.5281/zenodo.371512029

This project contains the following extended data:

- Figure S1.png (SMR-HEIDI analysis results for rs6651255 between BP and LDH)

- Figure S2.png (SMR-HEIDI analysis results for rs6651255 between BP and GSDMC expression in skeletal muscle (GTEx v6))

- Figure S3.png (SMR-HEIDI analysis results for rs6651255 between BP and FAM49B expression in Brain anterior cingulate cortex BA24 (GTEx v6))

- Figure S4.png (SMR-HEIDI analysis results for rs6651255 between BP and FAM49B expression in CD8 cell line (CEDAR))

- Figure S5.png (SMR-HEIDI analysis results for rs6651255 between BP and heel bone mineral) density (UKBB)

- Figure S6.png (SMR-HEIDI analysis results for rs6651255 between BP and disc problem phenotype (UKBB))

- Figure S7.png (SMR-HEIDI analysis results for rs6651255 between BP and height (UKBB))

Data are available under the terms of the Creative Commons Attribution 4.0 International license (CC-BY 4.0).

\section{Acknowledgements}

We thank Denis Gorev, Anna Torgasheva and Eugeny Pakhomov for help with summary level data collection, processing, and analyses. We thank Michel Georges for permission to use the CEDAR results for this work, and for discussion related to CEDAR. We also thank Natalia Aulchenko for help with the manuscript preparation.
1. Hoy $D$, March $L$, Brooks $P$, et al.: The global burden of low back pain: estimates from the Global Burden of Disease 2010 study. Ann Rheum Dis. 2014; 73(6): 968-74.

PubMed Abstract | Publisher Full Text

2. Vos T, Abajobir AA, Abate $\mathrm{KH}$, et al.: Global, regional, and national incidence, prevalence, and years lived with disability for $\mathbf{3 2 8}$ diseases and injuries for 195 countries, 1990-2016: a systematic analysis for the Global Burden of Disease Study 2016. Lancet. 2017; 390(10100): 1211-59. PubMed Abstract | Publisher Full Text | Free Full Text
3. Zheng CJ, Chen J: Disc degeneration implies low back pain. Theor Biol Med Model. 2015; 12: 24

PubMed Abstract | Publisher Full Text | Free Full Text

4. Kjaer P, Leboeuf-Yde C, Sorensen JS, et al:: An epidemiologic study of MRI and low back pain in 13-year-old children. Spine (Phila Pa 1976). 2005; 30(7): 798-806. PubMed Abstract | Publisher Full Text

5. Sambrook PN, MacGregor AJ, Spector TD: Genetic influences on cervical and lumbar disc degeneration: a magnetic resonance imaging study in twins. 
Arthritis Rheum. 1999; 42(2): 366-72. PubMed Abstract | Publisher Full Text

6. Battié MC, Videman T, Gill K, et al: 1991 Volvo Award in clinical sciences. Smoking and lumbar intervertebral disc degeneration: an MRI study of identical twins. Spine (Phila Pa 1976). 1991; 16(9): 1015-21. PubMed Abstract | Publisher Full Text

7. Battié MC, Haynor DR, Fisher LD, et al:: Similarities in degenerative findings on magnetic resonance images of the lumbar spines of identical twins. $J$ Bone Joint Surg Am. 1995; 77(11): 1662-70. PubMed Abstract | Publisher Full Text

8. Williams FM, Popham M, Livshits G, et al:: A response to Videman et al., "challenging the cumulative injury model: positive effects of greater body mass on disc degeneration". Spine J. 2010; 10(1): 571-2; author reply 572. PubMed Abstract | Publisher Full Text

9. MacGregor AJ, Andrew T, Sambrook PN, et al:: Structural, psychological, and genetic influences on low back and neck pain: a study of adult female twins. Arthritis Rheum. 2004; 51(2): 160-7. PubMed Abstract | Publisher Full Tex

10. Hartvigsen J, Christensen K, Frederiksen $\mathrm{H}$, et al.: Genetic and environmental contributions to back pain in old age: a study of 2,108 danish twins aged 70 and older. Spine (Phila Pa 1976). 2004; 29: 897-901; discussion 902. PubMed Abstract | Publisher Full Text

11. Videman T, Battié MC, Gibbons LE, et al:: Associations between back pain history and lumbar MRI findings. Spine (Phila Pa 1976). 2003; 28(6): 582-8. PubMed Abstract | Publisher Full Text

12. Battié MC, Videman T, Levalahti E, et al.: Heritability of low back pain and the role of disc degeneration. Pain. 2007; 131(3): 272-80. PubMed Abstract | Publisher Full Text

13. Nyman T, Mulder M, lliadou A, et al:: High heritability for concurrent low back and neck-shoulder pain: a study of twins. Spine (Phila Pa 1976). 2011; 36(22): E1469-76.

PubMed Abstract | Publisher Full Text

14. MacGregor AJ, Andrew T, Sambrook PN, et al:: Structural, psychological, and genetic influences on low back and neck pain: a study of adult female twins. Arthritis Rheum. 2004; 51(2): 160-7. PubMed Abstract | Publisher Full Text

15. Kalichman L, Hunter DJ: The genetics of intervertebral disc degeneration Familial predisposition and heritability estimation. Joint Bone Spine. 2008 75(4): 383-7.

PubMed Abstract | Publisher Full Text

16. Livshits G, Popham M, Malkin I, et al: Lumbar disc degeneration and genetic factors are the main risk factors for low back pain in women: the UK Twin Spine Study. Ann Rheum Dis. 2011; 70(10): 1740-5. PubMed Abstract | Publisher Full Text | Free Full Text

17. Suri P, Palmer MR, Tsepilov YA, et al.: Genome-wide meta-analysis of 158,000 individuals of European ancestry identifies three loci associated with chronic back pain. PLOS Genet. 2018; 14(9): e1007601. PubMled Abstract | Publisher Full Text | Free Full Text

18. Freidin MB, Tsepilov YA, Palmer M, et al:: Insight into the genetic architecture of back pain and its risk factors from a study of 509,000 individuals. Pain. 2019 ; 160(6): 1361-1373.

PubMed Abstract | Publisher Full Text | Free Full Text

19. Bjornsdottir G, Benonisdottir S, Sveinbjornsson G, et al:: Sequence variant at $8 \mathrm{q} 24.21$ associates with sciatica caused by lumbar disc herniation. $\mathrm{Nat}$ Commun. 2017; 8: 14265 .

PubMed Abstract | Publisher Full Text | Free Full Text

20. GTEx Consortium, Laboratory DA \& Coordinating C (LDACC)—Analysis WG, Statistical Methods groups-Analysis Working Group, et al.: Genetic effects on gene expression across human tissues. Nature. 2017; 550(7675): 204-213. PubMed Abstract | Publisher Full Text | Free Full Text

21. Liu B, Gloudemans MJ, Rao AS: Ingelsson E and Montgomery SB.Abundant associations with gene expression complicate GWAS follow-up. Nat Genet. 2019; 51(5): 768-769.

PubMed Abstract | Publisher Full Text | Free Full Text

22. Nica AC, Montgomery SB, Dimas AS, et al: Candidate causal regulatory effects by integration of expression QTLs with complex trait genetic associations. PLoS Genet. 2010; 6(4): e1000895.

PubMed Abstract | Publisher Full Text | Free Full Text

23. Hormozdiari F, Van De Bunt M, Segre AV, et al: Colocalization of GWAS and eQTL signals detects target genes. Am J Hum Genet. 2016; 99(6): 1245-1260. PubMed Abstract | Publisher Full Text | Free Full Text

24. Zhu Z, Zhang F, Hu H, et al.: Integration of summary data from GWAS and eQTL studies predicts complex trait gene targets. Nat Genet. 2016; 48(5): 481-7. PubMed Abstract | Publisher Full Text

25. Giambartolomei C, Vukcevic D, Schadt EE, et al.: Bayesian test for colocalisation between pairs of genetic association studies using summary statistics. PLOS Genet. 2014; 10(5): e1004383.

PubMed Abstract | Publisher Full Text | Free Full Text

26. Westra HJ, Peters MJ, Esko T, et al:: Systematic identification of trans eQTLs as putative drivers of known disease associations. Nat Genet. 2013; 45(10): 1238-43.

PubMed Abstract | Publisher Full Text | Free Full Text

27. Lonsdale J, Thomas J, Salvatore M, et al:: The Genotype-Tissue Expression (GTEx) project. Nat Genet. 2013; 45(6): 580-5.

PubMed Abstract | Publisher Full Text | Free Full Text

28. Hemani G, Zheng J, Elsworth B, et al:: The MR-Base platform supports systematic causal inference across the human phenome. eLife. 2018; 7: pii: e34408. PubMed Abstract | Publisher Full Text | Free Full Text

29. Williams FMK, Tsepilov YA, Freidin M, et al.: Figures S1-S7. SMR-HEIDI analysis results for 8q24.21 locus between BP and selected phenotypes. Zenodo. http://www.doi.org/10.5281/zenodo.3715120

30. Williams FMK, Tsepilov YA, Freidin M, et al: Tables S2-S3. SMR-HEIDI results for 8q24.21 locus between back pain and other phenotypes. [Data set] Zenodo. http://www.doi.org/10.5281/zenodo.3715027

31. Livshits G, Ermakov S, Popham M, et al.: Evidence that bone mineral density plays a role in degenerative disc disease: the UK Twin Spine study. Ann Rheum Dis. 2010; 69(12): 2102-6.

PubMed Abstract | Publisher Full Text | Free Full Text

32. Kundaje $\mathrm{A}$, Meuleman $\mathrm{W}$, Ernst $\mathrm{J}$, et al.: Integrative analysis of 111 reference human epigenomes. Nature. 2015; 518(7539): 317-30. PubMed Abstract | Publisher Full Text | Free Full Text

33. Williams FMK, Tsepilov YA, Freidin M, et al:: Table S1. List of relevant studies of gene expression with available eQTL data. [Data set]. Zenodo. http://www.doi.org/10.5281/zenodo.3715005

34. Momozawa $Y$, Dmitrieva J, Théâtre E, et al.: IBD risk loci are enriched in multigenic regulatory modules encompassing putative causative genes. $\mathrm{Nat}$ Commun. 2018; 9(1): 2427

PubMed Abstract | Publisher Full Text | Free Full Text

35. Schmidt T, Samaras P, Frejno M, et al.: ProteomicsDB. Nucleic Acids Res. 2018 46(D1): D1271-81.

PubMed Abstract | Publisher Full Text | Free Full Text

36. Shang W, Jiang $Y$, Boettcher M, et al:: Genome-wide CRISPR screen identifies FAM49B as a key regulator of actin dynamics and T cell activation. Proc Natl Acad Sci U S A. 2018; 115(17): E4051-60. PubMed Abstract | Publisher Full Text | Free Full Text 


\section{Peer review discontinued peer review at F1000Research is author-driven. currently no reviewers are being invited. What does this mean?}

\section{Version 1}

Reviewer Report 23 September 2020

\section{https://doi.org/10.5256/f1000research.25092.r70799}

(C) 2020 Haglund L. This is an open access peer review report distributed under the terms of the Creative Commons Attribution License, which permits unrestricted use, distribution, and reproduction in any medium, provided the original work is properly cited.

\section{Lisbet Haglund}

Orthopaedic Research Laboratory, McGill University, Montreal, QC, Canada

The study "Sequence variation at 8q24.21 and risk of back pain" is well written and is addressing an important clinical problem. The design and data analysis are well performed.

It would be interesting to know more about the function of FAM49B and GDSMC and how a dysregulation could potentially lead to back pain. The fact that it is involved in mitochondrial dysregulation and reactive oxygen species may have implications for IVD degeneration and low back pain.

Is the work clearly and accurately presented and does it cite the current literature? Yes

Is the study design appropriate and is the work technically sound? Yes

Are sufficient details of methods and analysis provided to allow replication by others? Yes

If applicable, is the statistical analysis and its interpretation appropriate?

Yes

Are all the source data underlying the results available to ensure full reproducibility? Yes

Are the conclusions drawn adequately supported by the results? Yes

Competing Interests: No competing interests were disclosed. 
Reviewer Expertise: Molecular mechanisms of back pain

I confirm that I have read this submission and believe that I have an appropriate level of expertise to confirm that it is of an acceptable scientific standard.

The benefits of publishing with F1000Research:

- Your article is published within days, with no editorial bias

- You can publish traditional articles, null/negative results, case reports, data notes and more

- The peer review process is transparent and collaborative

- Your article is indexed in PubMed after passing peer review

- Dedicated customer support at every stage

For pre-submission enquiries, contact research@f1000.com 